\title{
Neonatal Administration of Memantine Enhances Social Cognition in Adult Rats Subjected to Early Maternal Deprivation
}

\author{
Ezequiel Uribe*, Eduardo Sánchez-Mendoza, Nayadoleni Nieves and Gustavo Merchor \\ Biophysics and Neuroscience Center, Behavioral Neurobiology Laboratory, \\ Biomedical and Technological Sciences, University of Carabobo, Valencia, Venezuela
}

\begin{abstract}
Schizophrenia is considered a neurodevelopmental disorder; however, all the available treatment options are used when the disease becomes clinically significant in adolescence or early adulthood. Using a developmental rat model of schizophrenia, we examined whether neonatal treatment with memantine, an NMDA receptor modulator, can improve schizophrenic-like symptoms in adulthood. Early maternal deprivation in rats produces deficits in social interaction behaviors in adulthood. In contrast, memantine administrated in neonatal rats subjected to early maternal deprivation significantly reduces deficits in social interaction behaviors in adulthood. These results raise the possibility that pharmacological treatment with memantine at the early developmental stage helps people with a risk to develop schizophrenic-like symptoms.
\end{abstract}

Key words: Schizophrenia, neuropharmacology, developing brain, glutamate, social cognition, neonatal

\section{INTRODUCTION}

Schizophrenia is considered a neurodevelopmental disorder, with onset during adolescence or early adulthood in $80 \%$ of cases [1]. It shows no clear signs of behavioral dysfunction during childhood; social isolation is frequent during prodromal period [2], and social cognition (SC) is severely impaired during the course of the disease [3]. More than half of the genes linked with schizophrenia are involved in events that occur in late prenatal and early post natal period, like neuronal migration and synaptic formation and stabilization [4], which suggests that the disease

Received June 10, 2016, Revised November 28, 2016,

Accepted November 30, 2016

${ }^{*}$ To whom correspondence should be addressed.

TEL: 58-241-8666259, FAX: 58-241-8685321

e-mail: euribe@uc.edu.ve / ezequiel.uribe@hotmail.com begin before adolescence but becomes clinically significant in this period; probably during prefrontal cortex maturation [5].

SC is a prefrontal function referred to the capacity of identify the mental status about conspecifics, which depend of a correct glutamatergic transmission [6], widely impaired in schizophrenia [7]. In this framework, major psychiatric disorder and specifically schizophrenia, cannot be cured after onset, but could be effectively prevented modulating neurotransmitters and/or their receptors during early developmental period [8]. Actually, all antipsychotic drugs such Haloperidol, a dopaminergic receptor antagonist, let the progression of the disease $[9,10]$, which suggest the needs to develop preventive treatment options; additionally the effects of this kind of antipsychotic drug on pre symptomatic phase of schizophrenia are unknown [8]. Memantine (MEM) is a N-Methyl D-Aspartate Receptor (NMDAR) low-affinity voltage-dependent uncompetitive antagonist, which is capable of regulate its high or low functioning states [11], usually disrupted in neonatal brains of
Copyright $($ ) Experimental Neurobiology 2016. www.enjournal.org
This is an Open Access article distributed under the terms of the Creative Commons Attribution Non-Commercial License (http://creativecommons.org/licenses/by-nc/4.0) which permits unrestricted non-commercial use, distribution, and reproduction in any medium, provided the original work is properly cited. 
rodents models of schizophrenia [12], rather than dopaminergic system, whose alteration seems to be the result of NMDA receptor dysfunction [13]. We propose that MEM administrated in neonatal period, is capable to prevent this situation and ensure a correct SC development. Previous report suggest the beneficial effect of MEM in social isolation in adult rat models on the glutamatergic dysfunction [14], but there are no evidence of pharmacological intervention in early stages of life.

\section{MATERIALS AND METHODS}

All animal handling was conducted in accordance to the Guide for the Care and Use of Laboratory Animals [15]. Pregnant Sprague-Dawley rats on the $12^{\text {th }}$ gestational day were obtained from our campus' animal facility and housed in individually cages in a light-dark 12/12 hours schedule with food and water ad libitum. The day of birth was designated as post natal day (PND) 0 .

On PND 2, dams were removed from their maternity cages to adjacent cages. Male pups were exposed separately, every day to 180 minutes (8:00 am to 11:00 am) period of maternal deprivation from PND 2 to 14 inclusive; in stainless steel cage $(6 \times 6 \times 12 \mathrm{~cm})$, preserving a body temperature of $36^{\circ} \mathrm{C}$.

Fifteen (15) pregnant rats, conform two working groups after the delivery. Maternal deprivation group (15 male pups) in which were applied the model of maternal deprivation during PND 2 to 14 (described above), involved the MEM sub group $(n=5)$ received MEM (10 $\mathrm{mg} \cdot \mathrm{Kg}^{-1}$ ), at neuroprotective dose [16], the saline solution sub group $(\mathrm{n}=5)$ and Haloperidol subgroup (HAL; conventional antipsychotic; $0.25 \mathrm{mg} \cdot \mathrm{Kg}^{-1}$ ) at psychoactive dose [14]. Non-maternal deprivation group $(n=15)$ did not take part in the maternal separation model, involved MEM subgroup $(n=5)$ received MEM (10 $\left.\mathrm{mg} \cdot \mathrm{Kg}^{1}\right), \mathrm{HAL}\left(0.25 \mathrm{mg} \cdot \mathrm{Kg}^{-1}\right)(\mathrm{n}=5)$ and saline treated group $(n=5)$. Drug's were calculated daily in basis to the body weight, and injected subcutaneously, immediately after three hours of isolation. Finally, pups got back to their mother. The final volume of the drug and solution injected were $0.1 \mathrm{~mL}$. In an earlier stage of the study, intraperitoneal injection caused severe injuries and death to the pups.

SC was evaluated trough the social interaction test (SIT, vide infra) which was applied at five (5) weeks (adolescent period) and 8 weeks of age (adult period).

\section{The social interaction test (SIT)}

SIT was performed according to Becker et al [17], using an open stainless steel cage $(52 \times 42 \times 20 \mathrm{~cm})$. The floor of the cage was uniformly distributed with rice shells. A digital camera (PCwebCam, Genius ${ }^{\mathrm{TM}}$ ) was placed over the cage and connected to a conventional laptop. The behavior of rats was recorded at 30 frames. ${ }^{-1}$ during 7 minutes. Ambient illumination was uniformly distributed at approximately 30 lux. After the third day of habituation in the test room, rats were familiarized with the SIT scene without recording. The laboratory was silent while the tests were performed.

SIT video recordings were analyzed with Tracker $^{\mathrm{TM}}$ software (Cabrillo College, US) measuring 4 different behavioral parameters: Active linking (AL), number of times in which one rat had the effective intention to take the other rat; recognition pattern (RP) the number of times in which the rat pass through the center of the arena (the central square area of $25 \%$ of the total arena surface), the total traveled distance (TTD) during 7 minutes were also measured during SIT, finally the distribution pattern (DP), the main location of each rat during SIT. All the parameters evaluate items of social cognition, such recognition of a conspecific in AL, social hierarchy in RP and DP and mate choice in TTD [18].

For additional animal behavior pattern detection the rat's walking pattern from SIT video recordings were plotted every 30 seconds. The cage arena in the SIT test was digitally divided in five (5) quadrants (one in the center and four corners). Total times the rat located in each quadrant were digitally counted.

\section{Statistical processing}

All data points are presented as mean \pm SD. Multiple group values were compared with non-parametric Kruskal-Wallis (KW) test with Dunn post-hoc test. Rat's behavioral pattern on the cage was characterized by the location counts on every quadrant by the average for each rat group and compared with non-parametric multivariable PERMANOVA test. The significance for all tests was set at $\mathrm{p}<0.05$.

\section{RESULTS}

\section{Active linking $(A L)$}

MEM administered during maternal deprivation did not show a significant increase in the AL compared to saline or HAL at the $5^{\text {th }}$ postnatal week (Fig. 1A). At the $8^{\text {th }}$ postnatal week, no difference was observed between saline and MEM treatment, but AL values for MEM group were significantly higher than those from the HAL treated group ( $\mathrm{p}=0.03$; Fig. 1B).

The group without maternal deprivation did not show difference among saline versus MEM or HAL treatment groups at the $5^{\text {th }}$ and $8^{\text {th }}$ postnatal week (Fig. 1A and B).

\section{Recognition pattern (RP)}

MEM but not HAL treatment reduced significantly at the $5^{\text {th }}$ 

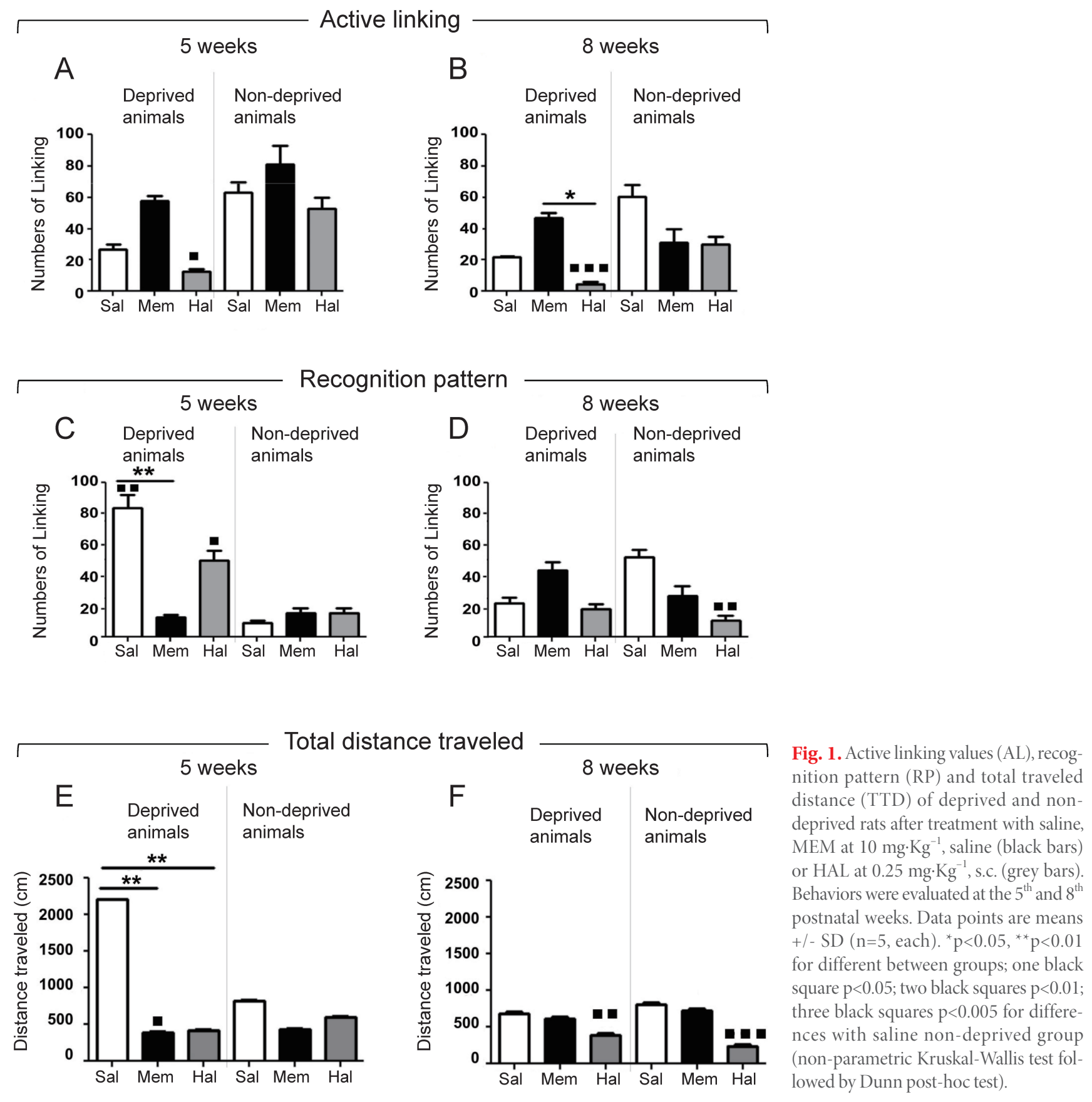

postnatal week, RP values compared to saline group $(\mathrm{p}=0.004)$. In the animal group without maternal deprivation, no difference was detected among MEM or HAL treated groups (Fig. 1C). In the maternal deprivation group at the $8^{\text {th }}$ postnatal week, there was no difference between MEM and HAL or between MEM and saline treated groups. For the groups without maternal deprivation, HAL but no MEM reduced significantly RP values compared with saline group ( $\mathrm{p}=0.04$; Fig. $1 \mathrm{E}$ and $\mathrm{F}$ ).

\section{Total traveled distance (TTD)}

For maternal deprivation condition, MEM ( $\mathrm{p}=0.001)$ and HAL $(p=0.003)$ reduced the TTD at 5 weeks of age compared to saline group, but not at 8 weeks of age. For groups without maternal deprivation, HAL reduced significantly TTD compared with saline group ( $\mathrm{p}=0.04$; Fig. 1D).

\section{Distribution pattern (DP)}

For maternal deprivation condition, MEM ( $\mathrm{p}=0.0083)$ and HAL 

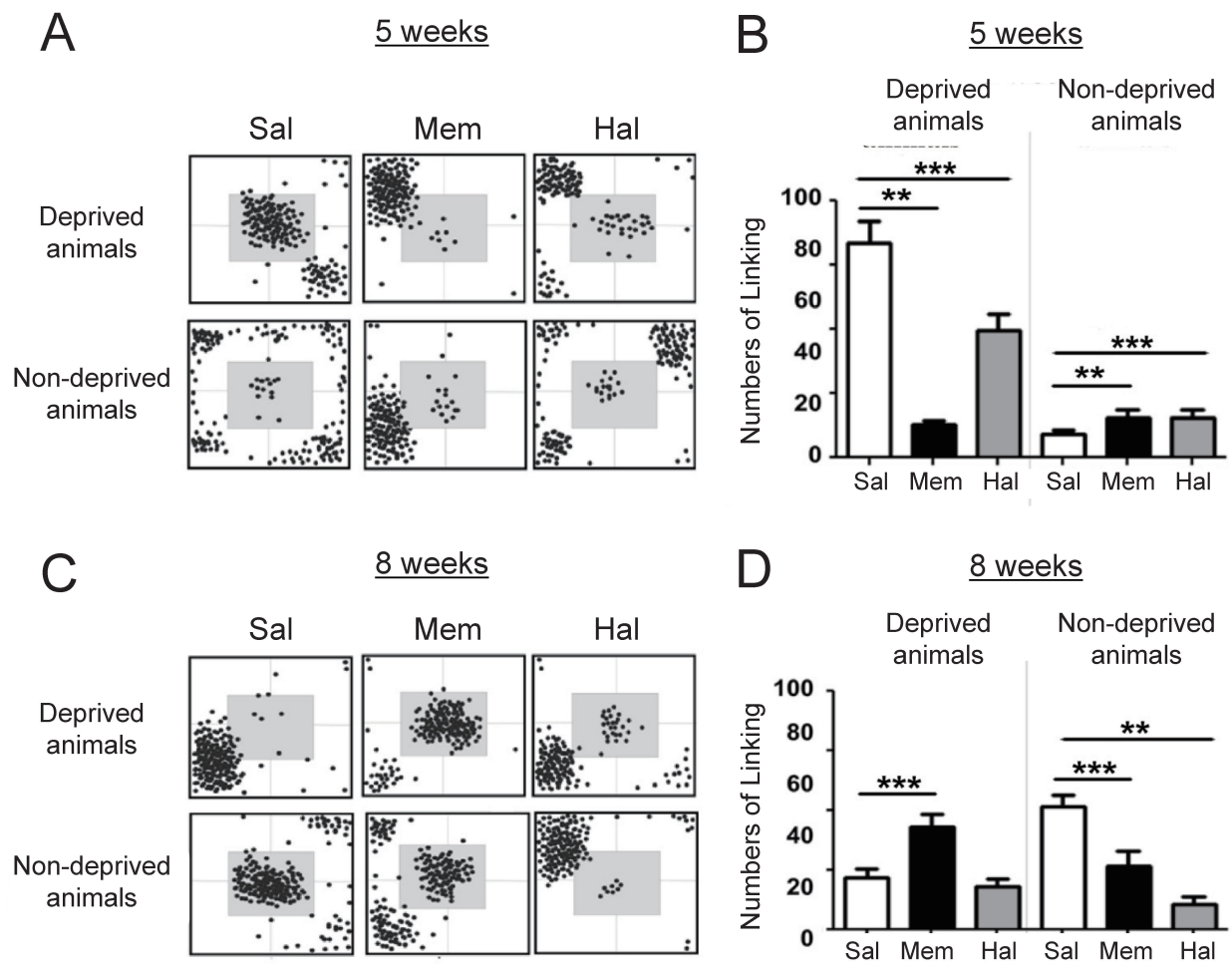

Fig. 2. Distribution pattern (DP) in the
open field of deprived and non-deprived
rats after treatment with SAL, MEM at
$10 \mathrm{mg} \cdot \mathrm{Kg}^{-1}$, s.c. or HAL at $0.25 \mathrm{mg} \cdot \mathrm{Kg}^{-1}$,
s.c. Behaviors were evaluated at the $5^{\text {th }}$
and $8^{\text {th }}$ postnatal weeks. Data points are
means $+/-\mathrm{SD}$ ( $\mathrm{n}=5$, each) ${ }^{* *} \mathrm{p}<0.01$,
${ }^{* * *} \mathrm{p}<0.005$ (non-parametric multivari-
able PERMANOVA test).

( $\mathrm{p}=0.0075)$ changed significantly the DP compared to saline group at 5 weeks of age. At 8 weeks of age, MEM $(p=0.0079)$ but not HAL ( $p=0.0746)$ changed the DP compared to saline at 8 weeks of age (Fig. 2A and B). For groups without maternal deprivation, HAL $(p=0.0076)$ and MEM $(p=0.0094)$ changed the DP at 5 weeks of age compared with saline group. At 8 weeks of age, MEM ( $\mathrm{p}=0.0066)$ and HAL $(\mathrm{p}=0.0096)$ change the mean distribution compared with saline group (Fig. 2C and D).

\section{DISCUSSION}

In the present study, MEM or HAL treatment at early postnatal stages was tested for the first time in the maternal deprivation rat model evaluating 4 different behavior parameters of SC [19], i.e., AL, RP, TTD and DP obtained from the social interaction test, in two critical periods (adolescence and adulthood), obeying the paradigm that SC is impaired in schizophrenia even before the onset of the disease [3]. Saline non-deprivation group normally displays high values of AL, low degree of recognition behavior, medium TTD and peripheral cage distribution pattern at five (5) weeks of ages (adolescent period). Those changes could occur during the normally immature prefrontal cortex [19]. Three weeks later (early adult period), AL and TTD remain constant, RP increases notably and the cage distribution changes to a central pattern, which suggest prefrontal cortex maturation [19]. The maternal deprivation group, shows a low amount of AL, high values of RP and TTD, and a central cage pattern at 5 weeks of ages; three weeks later AL persist low, RP and TTD showing a notably reduction while cage distribution pattern become angled, which suggest that the maternal deprivation at early neonatal stages induces a schizophrenic like behavior in early adult life ( 8 weeks of age), preceded of a prodromal disinhibition (5 weeks of age) [20]. These behavioral abnormalities strongly suggest a SC dysfunction, probably for incomplete maturation of prefrontal cortex [20].

Schizophrenia is a neurodevelopmental disorder which involves extensive abnormalities in prefrontal cortex, determining neuropsychological and behavioral alterations, emerging clinically in the adolescent period with a deficit in SC, just when prefrontal cortex is at the end of its maturation process $[5,21]$. The early maternal deprivation model induces prefrontal changes that persist in adult rat brain, generating behavioral disturbances in adult life that reminiscence schizophrenic's symptom $[22,23]$.

The pharmacological reversion by MEM of abnormalities in social cognition induced by early maternal deprivation, suggest that MEM effectively prevents social cognition impairment in adulthood. That beneficial effect is possible modulating the glutamatergic system in early neonatal period [4]. In the other hand, HAL induced a severe impairment of social cognition similar to those induced by the maternal deprivation, suggesting 
that HAL, given in neonatal period induces SC impairment in early adulthood and could represent by itself a new model of drug induced schizophrenic behavior; maybe when dopaminergic receptors type 2 are antagonized in neonatal period. Finally, this results stand out the possibility to develop pharmacological preventive treatment for schizophrenia to ensure the complete develop of SC in adult life.

\section{ACKNOWLEDGEMENTS}

Authors thank Antonio Eblen-Zajjur, MD., PhD., for critical Reading of the manuscript. Partially supported by Dirección de Investigación y Producción Intelectual, Facultad de Ciencias de la Salud, Universidad de Carabobo.

\section{REFERENCES}

1. Lehman AF, Lieberman JA, Dixon LB, McGlashan TH, Miller AL, Perkins DO, Kreyenbuhl J; American Psychiatric Association; Steering Committee on Practice Guidelines (2004) Practice guideline for the treatment of patients with schizophrenia, second edition. Am J Psychiatry 161:1-56.

2. Weiden PJ, Buckley PF, Grody M (2007) Understanding and treating "first-episode" schizophrenia. Psychiatr Clin North Am 30:481-510.

3. Dodell-Feder D, Tully LM, Hooker CI (2015) Social impairment in schizophrenia: new approaches for treating a persistent problem. Curr Opin Psychiatry 28:236-242.

4. Uribe E, Wix R (2011) Epigenetic control of the GABAergic interneurons migration and NMDA receptor functioning in schizophrenia. eNeurobiología 2:310811.

5. Woo TU (2014) Neurobiology of schizophrenia onset. Curr Top Behav Neurosci 16:267-295.

6. Green MF, Horan WP, Lee J (2015) Social cognition in schizophrenia. Nat Rev Neurosci 16:620-631.

7. Kantrowitz J, Javitt DC (2012) Glutamatergic transmission in schizophrenia: from basic research to clinical practice. Curr Opin Psychiatry 25:96-102.

8. Millan MJ, Andrieux A, Bartzokis G, Cadenhead K, Dazzan P, Fusar-Poli P, Gallinat J, Giedd J, Grayson DR, Heinrichs M, Kahn R, Krebs MO, Leboyer M, Lewis D, Marin O, Marin P, Meyer-Lindenberg A, McGorry P, McGuire P, Owen MJ, Patterson P, Sawa A, Spedding M, Uhlhaas P, Vaccarino F, Wahlestedt C, Weinberger D (2016) Altering the course of schizophrenia: progress and perspectives. Nat Rev Drug Discov 15:485-515.

9. Mier D, Kirsch P (2016) Social-cognitive deficits in schizophrenia. Curr Top Behav Neurosci (in press).

10. Bergh S, Hjorthøj C, Sørensen HJ, Fagerlund B, Austin S, Secher RG, Jepsen JR, Nordentoft M (2016) Predictors and longitudinal course of cognitive functioning in schizophrenia spectrum disorders, 10 years after baseline: The OPUS study. Schizophr Res 175:57-63.

11. Rammes G, Danysz W, Parsons CG (2008) Pharmacodynamics of memantine: an update. Curr Neuropharmacol 6:5578.

12. Jeevakumar V, Kroener S (2016) Ketamine administration during the second postnatal week alters synaptic properties of fast-spiking interneurons in the medial prefrontal cortex of adult mice. Cereb Cortex 26:1117-1129.

13. Beaulieu JM, Gainetdinov RR (2011) The physiology, signaling, and pharmacology of dopamine receptors. Pharmacol Rev 63:182-217.

14. Uribe E, Landaeta J, Wix R, Eblen A (2013) Memantine reverses social withdrawal induced by ketamine in rats. Exp Neurobiol 22:18-22.

15. Institute of Laboratory Animal Resources (US) (2011) Guide for the care and use of laboratory animals. 11th ed. National Academies Press, Washington, D.C.

16. Cabuk B, Etus V, Bozkurt SU, Sav A, Ceylan S (2011) Neuroprotective effect of memantine on hippocampal neurons in infantile rat hydrocephalus. Turk Neurosurg 21:352-358.

17. Becker A, Grecksch G, Bernstein HG, Höllt V, Bogerts B (1999) Social behaviour in rats lesioned with ibotenic acid in the hippocampus: quantitative and qualitative analysis. Psychopharmacology (Berl) 144:333-338.

18. Kaidanovich-Beilin O, Lipina T, Vukobradovic I, Roder J, Woodgett JR (2011) Assessment of social interaction behaviors. JVis Exp 2473.

19. Kolb B (1984) Functions of the frontal cortex of the rat: a comparative review. Brain Res 320:65-98.

20. Casey BJ, Jones RM, Hare TA (2008) The adolescent brain. Ann N Y Acad Sci 1124:111-126.

21. Kolb B, Mychasiuk R, Muhammad A, Li Y, Frost DO, Gibb R (2012) Experience and the developing prefrontal cortex. Proc Natl Acad Sci U S A 109 Suppl 2:17186-17193.

22. Girardi CE, Zanta NC, Suchecki D (2014) Neonatal stressinduced affective changes in adolescent Wistar rats: early signs of schizophrenia-like behavior. Front Behav Neurosci 8: 319.

23. Aksić M, Radonjić NV, Aleksić D, Jevtić G, Marković B, Petronijević N, Radonjić V, Filipović B (2013) Long-term effects of the maternal deprivation on the volume and number of neurons in the rat neocortex and hippocampus. Acta Neurobiol Exp (Warsz) 73:394-403. 